\title{
"We're all in the same boat": a qualitative study on how groups work in a diabetes prevention and management programme
}

Short title: Change processes in diabetes prevention and management groups

Aleksandra J. Borek ${ }^{1,2}$, Charles Abraham ${ }^{1,3}$, Colin J. Greaves ${ }^{1,4}$, Mark Tarrant ${ }^{1}$, Nikki Garner ${ }^{5}$, Melanie Pascale 5

${ }^{1}$ University of Exeter Medical School, University of Exeter, Exeter, UK

${ }^{2}$ Nuffield Department of Primary Care Health Sciences, University of Oxford, Oxford, UK

${ }^{3}$ School of Psychological Sciences, Faculty of Medicine, Dentistry and Health Sciences, University of Melbourne, Melbourne, Australia

${ }^{4}$ School of Sport, Exercise \& Rehabilitation Sciences, University of Birmingham, Edgbaston, UK

${ }^{5}$ Norfolk Diabetes Prevention Study, Norfolk \& Norwich University Foundation Healthcare Trust, Norwich, UK

* Corresponding author: Aleksandra Borek, Nuffield Department of Primary Care Health Sciences, University of Oxford, Radcliffe Observatory Quarter, Woodstock Road, OX2 6GG, Oxford, UK; email: Aleksandra.borek@phc.ox.ac.uk; tel.: +44 (0)1865 289337

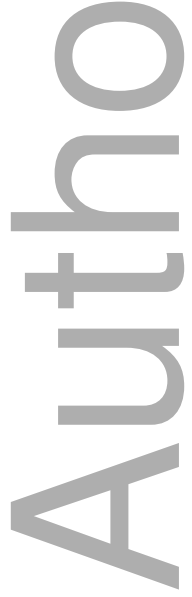

This is the author manuscript accepted for publication and has undergone full peer review but has not been through the copyediting, typesetting, pagination and proofreading process, which may lead to differences between this version and the Version of Record. Please cite this article as doi: 10.1111/BJHP.12379

This article is protected by copyright. All rights reserved 


\section{Declarations}

\section{Authors' contributions}

$\mathrm{AB}$ designed the study, conducted and analysed the interviews, and wrote and revised the manuscript. $\mathrm{CA}$ and $\mathrm{CG}$ contributed to the study design. CA raised funding, was lead supervisor of $\mathrm{PhD}$ student $\mathrm{AB}$, contributed to the interpretation of the data and writing of the manuscript. CG and MT advised on the study and commented on manuscript drafts. NM and MP advised on adaptation of the study to comply with the NDPS protocols, and facilitated access to NDPS participants. All authors approved the final manuscript.

\section{Acknowledgments}

We thank those who participated in this study. We also thank Dr Sammyh Khan and Professor Nicky Britten for helpful discussions that shaped out thinking.

\section{Funding}

This work presents independent research funded by A. Borek's PhD studentship from the University of Exeter, the UK National Institute for Health Research (NIHR) Collaboration for Leadership in Applied Health Research and Care of the South West Peninsula (PenCLAHRC), and C. Greaves' Career Development Fellowship (CDF-2012-05-029). The views expressed in this paper are those of the authors and not necessarily those of NIHR, the UK Department of Health or the University of Exeter.

\section{Conflict of interest}

The authors declare that they have no competing interests.

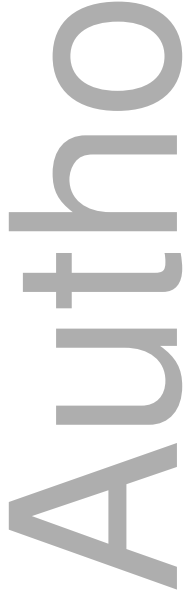




\section{Abstract}

4 Objectives: Although many health interventions are delivered in groups, it is unclear how

\section{"We're all in the same boat": a qualitative study on how groups work} in a diabetes prevention and management programme group context can be best used to promote health-related behaviour change and what change processes are most helpful to participants. This study explored participants' experiences of attending type 2 diabetes prevention and management programme, and their perceptions of how group participation influenced changes in diet and physical activity.

\section{Design: Qualitative.}

Methods: Semi-structured telephone interviews were conducted with 20 participants (twelve men) from nine groups in the Norfolk Diabetes Prevention Study. Interviews were audio recorded, transcribed verbatim and analysed using thematic analysis in NVivo.

Results: Participants benefited from individual change processes, including information provision, structuring and prioritizing health goals, action planning, self-monitoring, and receiving feedback. They also benefited from group processes, including having a common purpose, sharing experiences, making social comparisons, monitoring and accountability, and providing and receiving social support. Participants' engagement with, and benefits from, the groups were enhanced when there was a supportive group context (i.e., group cohesion, homogeneous group composition and a positive group atmosphere). Optimal facilitation to develop an appropriate group context and initiate effective change processes necessitated good facilitator interpersonal and professional skills, credibility and empathy, and effective group facilitation methods. Participants reported developing a sense of responsibility and making behaviour changes that resulted in improvements in health outcomes and weight loss. Conclusions: This study highlights the role of individual and group processes in facilitating health-promoting behaviour change, and the importance of group context and optimal facilitation in promoting engagement with the programme.

Keywords: type 2 diabetes, diabetes prevention, diabetes management, behaviour change, group interventions, group dynamics, qualitative methods, interviews, thematic analysis 


\section{Background}

The increasing prevalence of type 2 diabetes, its negative health consequences and health care costs has made diabetes prevention an international public health priority (World Health Organization, 2013). Type 2 diabetes can usually be delayed or prevented, and sometimes reversed, through lifestyle changes, such as adopting a healthier diet, increasing physical activity, and through weight reduction (Schwarz, Greaves, Lindström, Yates, \& Davies, 2012). Evidence shows that lifestyle interventions delivered in real-world settings are effective in reducing the risk of type 2 diabetes (Dunkley et al., 2014). For example, the intensive one-to-one US Diabetes Prevention Program lifestyle intervention resulted in 58\% lower diabetes incidence (DPP Research Group, 2002). However, delivering multiple one-toone sessions by healthcare professionals makes such interventions costly and difficult to implement on a large scale.

Groups are commonly used to deliver lifestyle and self-care interventions (Greaves \& Campbell, 2007; Sharma, 2007). They can facilitate weight loss with the most successful high-quality studies showing up to $8 \mathrm{~kg}$ weight loss at 6 and 12 months (Borek, Abraham, Greaves, \& Tarrant, 2018). In diabetes self-management, group interventions result in weight loss, reduced blood glucose, improved diabetes knowledge and reduced need for medication, and were found more effective than usual care and individual interventions (Deakin, McShane, Cade, \& Williams, 2009; Odgers-Jewell et al., 2017). Group-based healthpromotion interventions might be effective by providing opportunities for facilitating individual as well as social (inter-personal) change processes, such as intragroup support, social comparisons or social learning and modelling (Borek \& Abraham, 2018). Moreover, groups offer a potential for cost saving. For example, delivering the US Diabetes Prevention Program in groups by non-medical facilitators reduced personnel costs by $50 \%$ while showing similar clinical results (Ackermann, Finch, Brizendine, Zhou, \& Marrero, 2008).

Systematic reviews attempt to identify effective components of diet and physical activity interventions (e.g., Dombrowski et al., 2012; Olander et al., 2013). However, such systematic reviews do not consider participants' own perceptions and experiences of the change processes. Moreover, the categorizations employed in such reviews often fail to clarify the change processes unfolding within interventions and the change techniques or methods used to generate them (Abraham, 2016; Abraham \& Michie, 2008). This is especially problematic when investigating change mechanisms operating in group interventions because descriptions of group characteristics (e.g., group composition, facilitator characteristics, or facilitation style) and of the logic model on which group design 
1 was based are often incomplete (Borek et al., 2018; Borek, Abraham, Smith, Greaves, \& Tarrant, 2015).

Qualitative studies of participants' experiences have provided insights into how such groups generate change and benefit. For example, participants in group-based diabetes prevention interventions valued peer support, group ethos and sharing of experiences (Ljung, Olsson, Rask, \& Lindahl, 2013; Penn, Dombrowski, Sniehotta, \& White, 2013; Kok et al., 2019). Group support was also listed by key stakeholders as one of the benefits of the recent roll-out of the national diabetes prevention programme in England (Penn et al., 2018). Similarly, studies of group-based chronic disease self-management programmes showed that groups helped enhance self-efficacy for using self-management and coping strategies by providing opportunities for sharing experiences, social comparisons, and support (Abraham \& Gardner, 2009; Barlow, Bancroft, \& Turner, 2005; Rogers, Gately, Kennedy, \& Sanders, 2009). Yet, the potential benefits of group support may not always be maximised by group facilitators in such interventions (Borek et al., In Press; Hughes et al., 2018). Research has also shown that developing a shared social identity is important in promoting health and engagement with group interventions (Tarrant, Hagger, \& Farrow, 2012; Tarrant et al., 2017). However, previous studies have explored participants' experiences of health interventions in general. These studies have not focused on exploring how group-specific factors affect change processes, how change processes operate in group interventions, for whom they might be most beneficial, and what might affect their effectiveness in groups.

This present study aimed to explore the experiences of participants attending group sessions in the Norfolk Diabetes Prevention Study (NDPS) to identify participants' experiences of group participation and their perceptions of how groups can generate lasting behaviour change, and to contribute to process evaluation of the NDPS. Our research questions were:

1) What did the participants in the NDPS hope to get out of the group programme?

2) What were their experiences and perceptions of group participation?

3) What did they find helpful and unhelpful in group participation in relation to making behaviour changes?

\section{Methods}

\section{The Norfolk Diabetes Prevention Study (NDPS)}

NDPS is a randomized controlled trial of a group-based lifestyle intervention for people at risk of, and with newly diagnosed, type 2 diabetes (Murray, Abadi, Blair, Dunk, \& Sampson, 2011; Pascale et al., 2017). The lifestyle intervention included six fortnightly, two-hour-long, 
1 group sessions. The group sessions comprised up to 15 mixed-sex participants who sat in a semi-circle facing the facilitator. The sessions involved interactive presentations and group discussions focused on understanding diabetes and its prevention/control, making dietary changes, increasing physical activity, and, where appropriate, weight loss. They were delivered by one of four female (aged 25 to 53), trained, non-medical facilitators with backgrounds in health promotion, nutrition, sports science and/or public health. After the six core education sessions the participants were offered up to 15 maintenance group sessions held every eight weeks, including progress review, group discussions, action planning and supervised group exercise.

The National Research Ethics Committee for East of England approved this qualitative study as part of the NDPS protocol (Ref. 10/H0301/55).

\section{Participant recruitment}

NDPS participants were invited for an interview. The facilitators or research assistants distributed recruitment packs (including an invitation letter, information leaflet, consent form, reply slip and pre-stamped return envelope) to all participants completing the sixth education session at the time of recruitment for this qualitative study. Interested participants were asked to reply directly to the researcher conducting the interviews who was otherwise not involved in the NDPS. Purposive sampling was used to recruit an equal number of men and women, from a range of different groups (to ensure variation of experiences), among those who had completed the six education sessions (to ensure sufficient exposure to the intervention and group development). All participants provided written consent to be interviewed.

\section{Data collection}

Telephone interviews were conducted between May and November 2014 by the first author using a semi-structured interview schedule (Additional Document 1). The following key topics were discussed: motivations to participate in, and expectation of, the group; what happened in the group sessions; perceptions of the group and the facilitator, impact of the programme, including most helpful and unhelpful aspects, and suggestions for improvement.

28 The interviews began with general questions followed by more specific questions and prompts for clarification and examples. They were audio-recorded, transcribed verbatim, and the transcripts were checked for accuracy by the first author.

\section{Analysis}

Transcripts were uploaded to NVivo software (v.10) and analysed using thematic analysis taking a realist approach to identifying participants' experiences on a semantic level (as described by Braun \& Clarke, 2006), and then interpreting them in the context of theories 
1 and research on change processes in groups. After thorough familiarization with the data through listening to all recordings and reading and re-reading the transcripts, five interviews were initially coded inductively line-by-line. The lower-level codes were grouped into subthemes and themes related to the research questions. Remaining transcripts were then coded deductively, using the hierarchical coding framework, but adding new codes, when identified, and paying attention to deviant cases. Data related to each code and theme was reviewed, checked and re-coded if necessary, and the themes were defined. Data saturation at the level of sub-themes was considered when multiple quotes that allowed theoretical interpretation were available for that sub-theme. Throughout the analysis, reflective analytic memos were made, and the developing thematic framework and coding decisions were discussed frequently and in detail between the first two authors until consensus was reached. Findings were also shared with team members for critical review.

\section{Results} interviews lasted between 22 and 55 (mean 37) minutes. Fifteen participants were at risk of diabetes and five had newly diagnosed diabetes, and a majority of them were overweight or obese (mean BMI 29.5, 15 had BMI>25). Participants' characteristics are provided in Additional Document 2 and were representative of the NDPS sample. Each group was assigned a letter and gender-appropriate pseudonyms were used.

Analyses generated 30 sub-themes grouped into five overarching themes, summarised in Figure 1: (1) participants' motivations for participating, (2) identified change processes including both individual and group-specific processes, (3) perceptions of group context, (4) optimal facilitation strategies, and (5) impact of group participation. Below we report the results by each overarching theme and sub-theme, and illustrate with quotes. Additional quotes $(\mathrm{Q})$ supporting the analyses are provided in Additional Document 3.

\section{Participants' Motivations}

Improving Health, Preventing or Controlling Diabetes, and Losing Weight: All respondents wanted to improve their health and prevent, or control, diabetes (e.g., "to improve your own situation really” [Henry, G], quotes Q1.1-4 in Additional Document 3).

30 Some felt that they already led a healthy lifestyle and saw the programme as an opportunity to further improve, or "tweak", their health (Q1.5), gain new information about diabetes

32 (Q1.6) and lose weight (Q1.7). Those who had previous experience of commercial weight-

33 loss groups hoped the programme would be better at educating and helping them with longer34 term health improvement (Q1.8-9). 
Contributing to Research: In addition to improving health, some participants wanted

2 to help others by participating in research (e.g., "if it helps to make me better... and to help

3 others along the line, that would make me happy" [Harriet, F], Q1.10-11).

Intrinsic and Post-Diagnostic Motivation: Some, mainly male, respondents felt they had the motivation, willpower or determination to make changes and improve their health and so did not see group sessions as bolstering motivation (e.g., "I probably would have done it anyway" [John, A], Q1.12-14). Few reported that receiving a "diagnosis" of pre-diabetes or diabetes motivated them to make lifestyle changes while the programme prompted them to take action (Q1.15-16).

\section{Change processes}

Group participation was seen to generate behaviour change through individual change processes, which have been identified as important to diet and physical activity interventions (Abraham \& Michie, 2008), and group-specific change processes, which involved interpersonal interactions.

\section{Individual Change Processes}

Information Provision: All respondents found provision of information helpful (e.g., “you can learn a lot, you are given a lot of information" [Caroline, C], Q2.1). Some joined because they saw the programme as a source of information about health and diabetes (e.g., "All I cared really is the information. I have the willpower to do it" [Matt, D], Q2.2). For those who felt to be knowledgeable, or already having a healthy lifestyle (Q2.3), information provision in groups was experienced as repetitive (e.g., "I was thinking God when will they stop telling us because they repeat it such a lot" [Lucy, E], Q2.4-5) and not tailored to their personal needs and interests (Q2.6-7). Therefore, some respondents considered that providing at least some of the information individually or online would be helpful (Q2.8-9).

Structuring and Prioritising Health Goals: Participating in the programme helped some participants structure and prioritise their health goals and supported initiation of action (e.g., "the programme sort of got me going" [Adam, B], Q2.10-1). The sessions provided a regular, scheduled time to focus on and prioritise health (e.g., "it's about going regularly and making that time for myself" [Molly, G], Q2.12), and helped setting attainable goals (e.g., "little staging posts to aim for" [Harry, H], Q2.13-14).

Action Planning: Participants were advised to consider what, when, where, and with whom they would do to achieve their goals. For some this was helpful in translating motivation into action (e.g., "it did make you think... what I am personally going to do differently" [Henry, G], Q2.15-16). However, more respondents found writing down action 
1 plans repetitive (e.g., "it's just irritating. I decided right at the beginning what I was going to 2 do and I stuck with it" [Mary, A], Q2.17-18) or redundant (e.g., "I am not the person to write everything down... it's all in my head" [James, F], Q2.19-20). Others found it difficult as the pre-set format did not fit their circumstances, or due to lack of time or accountability (Q2.2122). Moreover, repetitively failing to fulfil action plans was perceived as undermining its importance and decreasing confidence (Q2.23).

Self-monitoring: Respondents rarely initiated talking about self-monitoring, but few of them reported monitoring their weight, diet or physical activity and finding it helpful (Q2.24-25)

Receiving Feedback: Observing success and receiving positive feedback, for example, in relation to weight, blood glucose or body composition, and was perceived as rewarding and bolstered motivation ("my blood sugar dropped by $10 \%$... it was really nice to get that sort of feedback... [that] there is a direct result" [Daniel, I], Q2.26-28).

Common Purpose: An important aspect of group participation was meeting other people in a similar situation and with similar challenges, "in the same boat" [Mary, A] (Q2.29-31). The shared goals of improving health and preventing or managing diabetes generated a shared, task-focused social identity (e.g., "We're in this together... we're all working to the same goal” [Lucy, E]), which validated participants' experiences (e.g., "You realise that you are not the only person who is having some sort of difficulties" [Helen, B]) and developing supportive relationships within the group (Q2.32-35).

Sharing Experiences: Recognition of being in a similar situation and having a common purpose enabled sharing experiences and provided opportunities for interpersonal learning and modelling (e.g., "cross-fertilisation of ideas in the group what people are doing and what the barriers are for them... a lot real life experience and guidance and ideas" [Daniel, I], Q2.36-38). It also facilitated group problem solving that bolstered self-efficacy (e.g., "giving you ideas and confidence about things" [Henry, G], Q2.39-42). However, some participants did not want to share their experiences with the group due to personal preference (Q2.41-42), concern with how others would perceive their experience (Q2.43) or when they perceived having little in common with other group participants (e.g., "I was the only one that wasn't a pensioner... I'd have got more out of it if there had been someone on the course... who was similar to me” [Molly, G], Q2.44).

Social Comparisons: Upward social comparisons, facilitated through sharing, enhanced motivation and self-efficacy (e.g., "when I see what that man must have put... to 
1 lose that ... that gives you enough confidence to carry on" [Dave, A], Q2.45-46). Downward social comparisons (e.g., with those who had diabetes) helped participants confront their own difficulties and motivated them to avoid health deterioration (Q2.47). However, for those who struggled to meet their goals, social comparisons could reduce self-efficacy (e.g., "listening to what everybody else is... achieving, and if you are not achieving anything, it's a bit demoralising” [Molly, G], Q2.48-50).

Monitoring and Accountability: Group sessions, which included weighing, provided a sense of accountability ("the thought that somebody was going to be checking up on you the next week that made you stick to it” [Helen, B], Q2.51-52) and promoted self-discipline and adherence ("the main thing is discipline of going every fortnight and being weighed" [Mary, A], Q2.53). However, accountability to the group was limited because weighing and action planning were undertaken in private. Some respondents speculated that greater social accountability would motivate action (e.g., "if you made it known to the group, you would do it more" [Lucy, E], Q2.54); others preferred keeping things private ("it's not meant to be a competition" [Harry, H], Q2.55-56).

Social Support: Social support in the groups was viewed as encouragement, sharing of suggestions, and reciprocal help, and was commonly reported as a benefit of group participation (e.g., "I just feel that you can support each other" [Tom, I], Q2.57-59). For those with limited social networks, group support seemed especially important by providing opportunities to create new supportive social relationships or buddy-up (Q2.60-61). Other participants reported on the value of supportive social networks outside of groups (Q2.62-63).

\section{Group Context}

Group Cohesion: Establishment of a group bond, or cohesion, appeared to vary across groups. Some participants perceived the group as bound only by the presence of the common purpose, relationships with other members as superficial, and lacked social involvement (e.g., "I don't see it as a social group in the sense that we are there for a purpose" [Caroline, C], Q3.1-3). By contrast, other participants reported developing new relationships in their groups, which was enhanced by engaging in informal social interaction (e.g., "You have the camaraderie and you sort of build up a bond with other members" [Tom, I], Q3.4-6).

Group Composition: Members' characteristics, such as age, socioeconomic background or body weight, influenced perceptions of group cohesion and opportunity to benefit from sharing and social comparisons. Groups with participants who were perceived to share certain characteristics enhanced perceptions of cohesion and benefits of sharing (e.g., "I've enjoyed their company actually and we all seem to be fairly similar, we're all retired... 
1 come from a similar background" [Will, I], Q3.7). On the contrary, heterogeneous groups resulted in us-them categorisations based on background (Q3.8-9), age (Q3.10-11), or weight

3 (e.g., "A couple of ladies there had a normal BMI like 22.5 or 23 and I thought well why they're there" [Caroline, $\mathrm{C}]$ ), and led to a mismatch between experiences and goals (Q3.12$14)$.

Group Atmosphere: Establishing a positive group atmosphere underpinned cohesive, supportive group contexts. This entailed open, polite and respectful interaction with a degree of equality in participants' contributions (e.g., "everyone was equally as involved and... comfortable and confident enough to speak up" [Tom, I], Q3.15-17). Humour and informal interaction helped make the sessions "socially enjoyable” [Jane, B], Q3.18-22). A positive group atmosphere facilitated engagement with the programme and could affect attendance or dropout (e.g. "If I didn't feel comfortable then ... I wouldn't have gone anymore” [Dave, A], Q3.23).

\section{Optimal Facilitation}

Facilitators' Interpersonal Skills and Group Facilitation Strategies: Facilitators were crucial to facilitating positive group atmosphere and developing group cohesion (e.g., "in a subtle way she made everyone feel comfortable, which again is a winning formula really" [Tom, I], Q4.1). Valued facilitators were described as friendly, approachable, positive, supportive and good at social interactions and listening (Q4.2-7). They encouraged discussions and interaction, used participants' names and made sessions enjoyable (e.g., "they were jolly and upbeat ... kept us all going” [Harry, H], Q4.8-10). Managing the group was seen as of equal importance to delivering the content of the intervention (e.g., "they've got to know how to handle the group ... their positive attitude complements ... the information they are giving" [Harriet, F], Q4.11). Facilitators were particularly valued for encouraging group participation and discussion (Q4.12-15).

Facilitators' Professional Competence and Programme Delivery Strategies: Facilitators were seen as professional, knowledgeable, prepared, and organised (Q4.16-19).

28 Participants stressed the importance of effective delivery and careful use of language devoid of jargon (e.g., "certain words like 'circuit training'... I think that might frighten you and push you away" [Daniel, I], Q4.20-22). Moreover, tailoring delivery to the needs of the group, rather than following a script, was valued (e.g., "the ones who are good are the ones who do go off on a tangent and follow things up with what people say" [Mary, A], Q4.23-25), as was an encouraging and challenging, rather than prescriptive, delivery style (e.g., "[The 
1 facilitator was] telling us what was within our best interests... in an informative way rather than sort of dictatorial” [Tom, I], Q4.26-29).

Facilitators' Credibility and Empathy: Perceived facilitators' credibility and ability to empathise were valued and were enhanced when the facilitators were seen to share similar characteristics or experiences with participants (e.g., "I felt she was quite credible because... she'd gone through this... she was a similar age to me and she was working”' [Molly, G], Q4.30-31). In contrast, larger differences between participants and facilitators led some respondents to question their facilitator's credibility and ability to empathise (Q4.32-33).

Facilitators' Group Assignment: New facilitators were sometimes introduced between the sessions and some respondents saw this as affecting their experience of the group and perceptions of group atmosphere, cohesion and development (e.g., "I wonder if we had the same facilitator each time... whether it would be different, one would be a lot more relaxed" [Mary, A], Q4.34-36).

\section{Impact of Group Participation}

Positive and Negative Experiences: Most participants had positive experiences and found the programme helpful and enjoyable (e.g., "I've really loved it, and enjoyed it, and I've learnt a lot, and it's helped me quite a lot' [Adam, B], Q5.1-4). However, a few respondents reported some negative experiences and suggestions for improvement. For example, the youngest, working participant, and the only respondent who did not lose weight, felt different from other group members and experienced disempowering social comparisons (e.g., "most of them were retired so I felt a bit like I couldn't do as much as them because of my commitments" [Molly, G], Q5.5). Another participant felt that that he did not benefit from the group setting because the group did not "gel" ("we've never really gelled as a group... socially we'd never be friends... a couple of them have been professional, and I... could put myself as the working class person... other people in the group just didn't seem to share any interests ... and the whole thing with the group was a bit of a waste of time") but he acknowledged that "individually [he] learnt a lot" [James, F] (Q5.6). Interestingly, this participant's perception of this particular group was not shared by other members of this group (e.g., "the atmosphere is very good, excellent" [Jack, F], Q5.7), illustrating that a "fit" between participants' needs, expectations and group facilitation can influence what individuals gain from participation.

Taking Responsibility: Groups helped participants take responsibility and develop intrinsic motivation (e.g., "at the end of the day we've got to provide our own motivation and our own sort of reasons for doing it" [Harry, H], Q5.8-9). However, some respondents, for 
1 whom the groups were an important source of support (e.g., through structuring, accountability or group support), regretted the loss of frequent group contact and were concerned about maintenance of personal change beyond group meetings (e.g., "as the sessions get... further apart... we find it harder to stick to it” [Helen, B], Q5.10-12).

Reported Behaviour Change, Weight Loss and Improved Health: All interviewees reported making dietary and physical activity changes (Q5.13-16), and many reported weight loss, lower body fat and reduced blood glucose level (Q5.17-20). Some participants also emphasised positive affect resulting from such change (e.g., "I actually feel a lot better ... it's made an awful lot of difference to me" [Matt, D], Q5.21-22), and wanting to maintain these positive changes (e.g., "it's a slow gradual weight loss... because then I will also keep it off" [Harriet, F], Q5.23).

\section{Discussion}

This study investigated participants' experiences of attending group sessions in the Norfolk Diabetes Prevention Study (NDPS). As illustrated in Figure 1, participants were motivated to improve their health and prevent, or control, diabetes (left hand-side box), and the programme strengthened and helped to internalize their motivation. The programme facilitated helpful individual and group-specific change processes (centre box). Participants' experiences were affected by the group context: group cohesion, composition and atmosphere, which could enhance or impede individual and group processes. Optimal facilitation achieved through facilitators' skills and delivery methods, and supported by facilitators' credibility, empathy and continued group assignment, were important in fostering beneficial change processes and creating a supportive group context. Most respondents had positive experiences and felt that it helped them make lifestyle changes and improve their health (right hand-side box).

Most participants were motivated to improve health and prevent, or manage, diabetes when they joined the programme. For some participants becoming aware of being at risk of, or having, diabetes during screening for the NDPS study increased motivation and commitment for behaviour change. A diagnosis of pre-diabetes or diabetes can be seen as a "teachable moment" (McBride, Emmons, \& Lipkus, 2003) and provide motivation for lifestyle change and a good opportunity for healthcare professionals to capitalize on, as shown also in other studies (Abel, Whitehead, \& Coppell, 2018; Vähäsarja et al., 2015; Youngs, Gillibrand, \& Phillips, 2016). Unsurprisingly, participants had different needs expectations, which shaped what they found to be most helpful. Information provision, valued by participants in many group-based health interventions (Abraham \& Gardner, 2009; 
1 Catalano, Dickson, Kendall, Kuipers, \& Posner, 2003; Ljung et al., 2013), was particularly

2 important to those who needed the information most (e.g., who perceived themselves to lack

3 knowledge about diabetes or pre-diabetes). For those who had a strong autonomous motivation providing information alone might have been sufficient to facilitate behaviour change. Similarly to Sebire et al. (2018), we found that participants reported both external and autonomous motivation for lifestyle change, and after the core sessions many participants reported having internalized motivation with a healthy lifestyle described as personally important, rewarding, and enjoyable. For other participants setting and structuring health goals, accountability to others, and group support and encouragement were helpful sources of controlled motivation (Sebire et al., 2018). Accountability to others can be helpful in both group-based (Metzgar, Preston, Miller, \& Nickols-Richardson, 2014) and one-to-one weightloss interventions (Hardcastle \& Hagger, 2011), and, together with opportunities for continuous and flexible attendance, is valued by participants in commercial weight-loss programmes (Allan, Hoddinott, \& Avenell, 2011). Thus, tailoring groups to participants' needs and motivations, and selecting participants who share needs may optimize group effectiveness.

Interestingly, the respondents had differing opinions about action planning. Selfregulatory change techniques (e.g. goal setting, action planning, implementation intentions, self-monitoring) have been associated with intervention effectiveness (e.g., Greaves et al., 2011), but some participants perceived them to be less helpful, at least in the manner they were operationalized in this intervention (e.g., having to use a pre-designed, written action plan in every session). Tailoring, or personalizing, such techniques to individual needs may facilitate better engagement. Moreover, discussing goals may be helpful not only to increase accountability but also to provide feedback on the quality of action plans. However, facilitators too may find goal-setting and action planning challenging and may need more specific training on it (Fredrix, Byrne, Dinneen, \& McSharry, 2018).

This study highlighted the important role of group processes in influencing participants' experiences of the programme. The group setting was particularly valued for providing an opportunity to meet people in a similar situation and with a shared purpose ("in the same boat"), which has been identified as critical in groups for people with chronic conditions (Andersen, Kohberg, Herborg, Søgaard, \& Roessler, 2014; Asprey, Paterson, \& White, 2012). This allowed sharing common experiences, helping to normalize and validate them, encouraged engagement, relationship formation, provision of emotional and practical support, and group problem solving. Such common purpose can establish shared social 
1 identity, which can facilitate accessing educational material, generate social support and motivate lifestyle change in weight-loss groups (Tarrant et al., 2017). A shared social identity has been linked with improved health outcomes in various group settings (Haslam, Jetten, Postmes, \& Haslam, 2009; Tarrant et al., 2012; Wakefield, Bickley, \& Sani, 2013). However, our study showed that some participants failed to develop a sense of shared social identity, seeing the relationships with other group members as superficial, particularly when they perceived lack of similar characteristics or goals with other group participants. Facilitation of group cohesion and relationship-building (especially in the first session) should be encouraged, and having "outlying" participants in the groups should be avoided. This should be anticipated at the intervention design stage (Tarrant et al., 2016).

Group support was seen as one of the main benefits of attending the programme, which is consistent with findings from other studies (Abraham \& Gardner, 2009; Gallagher, Kirkness, Armari, \& Davidson, 2012; Metzgar et al., 2014; e.g., Penn et al., 2013). Social support can affect personal change by reinforcing self-esteem and self-efficacy (Hogan, Linden, \& Najarian, 2002). Our findings suggest that group support may be particularly helpful to those with fewer or no sources of support outside of groups. However, maintaining new behaviour patterns after group termination is likely to be more difficult for those dependent on group support. Thus, offering longer-term support groups and encouraging "buddying-up" might be more beneficial for people with weak support networks, while encouraging engagement of social support outside the group may be important for those with existing support networks.

We found that participants' perceptions of, and engagement with, groups depended on supportive group context and effective group facilitation. Group context influenced how beneficial group processes were: establishing a trusting but challenging environment can enhance benefits of sharing experiences (“disclosures") and receiving feedback (Smith, 1980), whereas comparing with similar others can foster performance (Festinger, 1954), thus facilitating personal change. The facilitators' role was crucial in developing group cohesion, positive group atmosphere, and facilitating individual and group change processes. This highlights the need for facilitators to have strong interpersonal and group management skills, and to be trained not only in delivering content but in collaborative and effective group facilitation (Avery, Whitehead, \& Halliday, 2016; Bligh, Pearce, \& Kohles, 2006).

Finally, it is also important to draw attention to potentially negative effects of group participation. Lack of individual tailoring was seen as a disadvantage of group context, in some cases, impeding individual learning and behaviour change. Thus, for some participants, 
1 particularly those with more complex health conditions, individual approaches might be preferred to groups (Greaves \& Campbell, 2007). Moreover, a perceived lack of "fit" with the group might hinder the benefits of group participation. Similarly, making disempowering social comparisons might decrease self-efficacy among those who struggle with achieving their goals. Failing to establish group cohesion and a positive group atmosphere might decrease engagement with the programme, leading to lower attendance and retention. This is particularly important as negative group dynamics, such as group conflict, have been linked with lower weight loss, attendance and adherence (Nackers et al., 2015).

Limitations of this study mean the findings should be interpreted with caution. Participants were recruited from among those who completed the six educational sessions to ensure exposure to different sessions and group development. For ethical and practical reasons we were unable to contact and recruit participants who dropped out from the programme. It is possible that our respondents were more motivated to attend the groups and make behaviour changes, more satisfied with the programme and experienced more benefits than participants who dropped out. Exploring experiences of the participants who drop out from group programmes and have low attendance is likely to provide further insight into how group interventions work and should be included in future research. Moreover, the respondents, although representative of the NDPS participants, were predominately older-age and White-British ethnicity. Interviewing participants in more ethnically diverse groups or communities would be informative, particularly in relation to understanding group composition and heterogeneity. The coding was conducted by the first author. As is usual in thematic analyses, no inter-coder reliability checks were conducted. Nonetheless, the coding themes, coding framework and interpretation were discussed frequently and in detail between the first two authors to reach consensus and other members of the team contributed through critical review. We were also limited in identifying for whom certain change processes in groups might be most effective. This was partly due to the relatively small, homogeneous sample from one group-based intervention, and limitations inherent in a qualitative study design in identifying associations between change processes and interventions outcomes.

Nonetheless, to our knowledge, this study is unique in its focus on the different aspects of group participation, and the role of groups in affecting participants' experiences of, and benefits from, a group-based type 2 diabetes prevention and management intervention. Data saturation was achieved with the reported themes being validated by multiple quotes representing views of different participants from various groups. Our results are validated by similar findings of qualitative studies with different populations in various health contexts, 
1 for example, diabetes prevention in Sweden (e.g., Ljung et al., 2013), weight loss in Australia 2 (e.g., Gallagher et al., 2012), self-management of diabetes in the US (e.g., Baig et al., 2012) 3 and of chronic diseases in Shanghai (e.g., Fu, Ding, McGowan, \& Fu, 2006).

As with any qualitative research, the coding, interpretation and presentation of the data was influenced by the researchers' interests and knowledge of related theories and research. The study was conducted with the NDPS participants and the authors were aware of the intervention design, which offered an opportunity to explore how it was experienced by the participants in comparison with how it was intended to work as part of process evaluation. The later, more interpretative stages, were also influenced by ongoing research on change processes in group-based interventions by the authors (Borek \& Abraham, 2018). For example, the themes and sub-themes were interpreted and named in the light of existing behaviour change and group dynamics literature. This helped to progress the data analysis from descriptive to interpretative and contribute to current theories and applied research.

The results suggest a series of practical recommendations for designers of such group interventions. (1) Participants' needs should be matched with intervention delivery methods, with less intense interventions offered instead of, or in addition to, groups. (2) Techniques for facilitating group-specific change processes and a supportive group context should be specifically built into the design of group-based interventions. For example, based on our findings, group-specific change processes can be facilitated by identifying and specifying shared goals by group members, prompting sharing experiences and group problem solving (encouraging the group to identify potential solutions), providing opportunities for feeling accountable to the group (e.g., inviting participants to share and review goals with the group), and encouraging mutual social support to each other (e.g., prompting buddy-ups). Supportive group contexts might also be facilitated by providing opportunities for informal social interaction (e.g., before sessions, in breaks), using humour, or establishing and reinforcing group norms of respect and trust. (3) Group composition and person - group "fit" should be considered when designing group interventions, and can be enhanced by maximizing similarities between group participants. (4) Facilitators should have good interpersonal and collaborative leadership skills as well as professional skills and should be comprehensively trained in all aspects of effective group facilitation. (5) Facilitators should be credible (e.g., have similar characteristics and/or experiences, and professional credibility) and have an ability to empathize. (6) Groups should be planned and facilitated to optimize personal change by generating group cohesion, trust and support combined with challenge and comparison, while highlighting autonomous motivation and personal responsibility for 
1 change (Smith, 1980). Our study therefore reiterates recommendations for greater attention to 2 the role of group processes when designing, delivering and evaluating group-based health 3 interventions (Borek \& Abraham, 2018; Haslam et al., 2018; Hoddinott, Allan, Avenell, \& 4 Britten, 2010; Murphy \& Johnson, 2006).

In conclusion, the study identified a number of individual and group change processes

6 and techniques, which were helpful in promoting lifestyle changes that are important for

7 preventing and managing type 2 diabetes. Findings showed the influence of participants'

8 needs and motivations, group characteristics and optimal facilitation on change processes and

9 participants' experiences of, and benefits from, group participation. The study highlights also

10 key issues that should be considered when designing, delivering and evaluating group-based

11 behaviour-change interventions, especially developing a sense of common purpose and

12 facilitating sharing of experiences, interpersonal learning and intra-group support.

14 Word count: 5,333; revised manuscript: 5,850 words

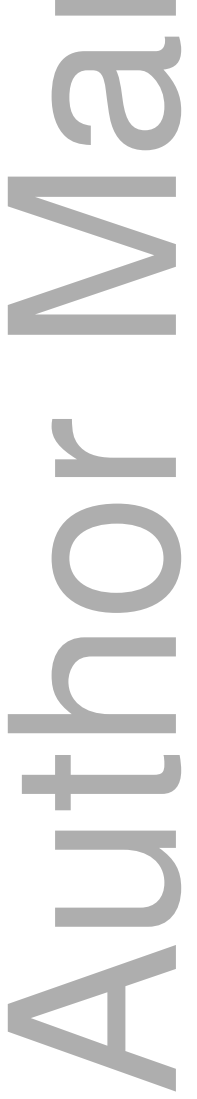




\section{References}

Abel, S., Whitehead, L. C., \& Coppell, K. J. (2018). Making dietary changes following a diagnosis of prediabetes: a qualitative exploration of barriers and facilitators. Diabetic Medicine, 35(12), 1693-1699. https://doi.org/10.1111/dme.13796

Abraham, C. (2016). Charting variability to ensure conceptual and design precision: A comment on Ogden (2016). Health Psychology Review, 10, 260-264. http://dx.doi.org/10.1080/17437199.2016.1190293

Abraham, C., \& Gardner, B. (2009). What psychological and behaviour changes are initiated by 'Expert Patient' training and what techniques are most helpful? Psychology \& Health, 24(10), 1153-1165. https://doi.org/10.1080/08870440802521110

Abraham, C., \& Michie, S. (2008). A taxonomy of behavior change techniques used in interventions. Health Psychology, 27(3), 379-387. https://doi.org/10.1037/0278$\underline{6133.27 .3 .379}$

Ackermann, R. T., Finch, E. A., Brizendine, E., Zhou, H., \& Marrero, D. G. (2008). Translating the Diabetes Prevention Program into the community: The DEPLOY pilot study. American Journal of Preventive Medicine, 35(4), 357-363. https://doi.org/10.1016/j.amepre.2008.06.035

Allan, K., Hoddinott, P., \& Avenell, A. (2011). A qualitative study comparing commercial and health service weight loss groups, classes and clubs. Journal of Human Nutrition and Dietetics, 24(1), 23-31. https://doi.org/10.1111/j.1365-277X.2010.01110.x

Andersen, L. N., Kohberg, M., Herborg, L. G., Søgaard, K., \& Roessler, K. K. (2014). "Here we're all in the same boat"- a qualitative study of group based rehabilitation for sicklisted citizens with chronic pain. Scandinavian Journal of Psychology, 55(4), 333342. https://doi.org/10.1111/sjop.12121

Asprey, A., Paterson, C., \& White, A. (2012). "All in the same boat": a qualitative study of patients' attitudes and experiences in group acupuncture clinics. Acupuncture in Medicine, 30(3), 163-169. https://doi.org/10.1136/acupmed-2012-010150

Avery, A., Whitehead, K., \& Halliday, V. (2016). How to Facilitate Lifestyle Change: Applying Group Education in Healthcare. John Wiley \& Sons.

Baig, A. A., Locklin, C. A., Wilkes, A. E., Oborski, D. D., Acevedo, J. C., Gorawara-Bhat, R., ... Chin, M. H. (2012). “One can learn from other people's experiences”: Latino adults' preferences for peer-based diabetes interventions. The Diabetes Educator, 38(5), 733-741. https://doi.org/10.1177/0145721712455700 
1 Barlow, J. H., Bancroft, G. V., \& Turner, A. P. (2005). Self-management training for people with chronic disease: A shared learning experience. Journal of Health Psychology, 10(6), 863-872. https://doi.org/10.1177/1359105305057320

Bligh, M. C., Pearce, C. L., \& Kohles, J. C. (2006). The importance of self-and shared leadership in team based knowledge work: A meso-level model of leadership dynamics. Journal of Managerial Psychology, 21(4), 296-318. https://doi.org/10.1108/02683940610663105

Borek, A. J., Abraham, C., Greaves, C. J., \& Tarrant, M. (2018). Group-based diet and physical activity weight-loss interventions: A systematic review and meta-analysis of randomised controlled trials. Applied Psychology: Health and Well-Being, 10(1), 6286. https://doi.org/10.1111/aphw.12121

Borek, A. J., \& Abraham, C. (2018). How do small groups promote behaviour change? An integrative conceptual review of explanatory mechanisms. Applied Psychology: Health and Well-Being, 10(1), 30-61. https://doi.org/10.1111/aphw.12120

Borek, A. J., Abraham, C., Smith, J. R., Greaves, C. J., \& Tarrant, M. (2015). A checklist to improve reporting of group-based behaviour-change interventions. BMC Public Health, 15(1), 963. https://doi.org/10.1186/s12889-015-2300-6

Borek, A. J., Smith, J. R., Greaves, C. J., Gillison, F., Tarrant, M., Morgan-Trimmer, S., McCabe, R., \& Abraham, C. (In Press). Developing and applying a framework to identify and understand "Mechanisms of Action in Group-based Interventions" (MAGI): A mixed-methods study. NIHR Efficacy \& Mechanism Evaluation. Available: www.journalslibrary.nihr.ac.uk/programmes/eme/1420203/\#

Braun, V., \&Clarke, V. (2006). Using thematic analysis in psychology. Qualitative Research in Psychology, 3(2), 77-101. https://doi.org/10.1191/1478088706qp063oa

Catalano, T., Dickson, P., Kendall, E., Kuipers, K., \& Posner, T. N. (2003). The perceived benefits of the chronic disease self-management program among participants with stroke: A qualitative study. Australian Journal of Primary Health, 9(3), 80. https://doi.org/10.1071/PY03028

Deakin, T., McShane, C. E., Cade, J. E., \& Williams, R. D. (2009). Group based training for self-management strategies in people with type 2 diabetes mellitus. Cochrane Database of Systematic Reviews, (2). https://doi.org/10.1002/14651858.CD003417.pub2

Dombrowski, S. U., Sniehotta, F. F., Avenell, A., Johnston, M., MacLennan, G., \& AraújoSoares, V. (2012). Identifying active ingredients in complex behavioural interventions 
for obese adults with obesity-related co-morbidities or additional risk factors for comorbidities: a systematic review. Health Psychology Review, 6(1), 7-32. https://doi.org/10.1080/17437199.2010.513298

DPP Research Group. (2002). Reduction in the incidence of type 2 diabetes with lifestyle intervention or metformin. The New England Journal of Medicine, 346(6), 393-403. https://doi.org/10.1056/NEJMoa012512

Dunkley, A. J., Bodicoat, D. H., Greaves, C. J., Russell, C., Yates, T., Davies, M. J., \& Khunti, K. (2014). Diabetes prevention in the real world: Effectiveness of pragmatic lifestyle interventions for the prevention of Type 2 Diabetes and of the impact of adherence to guideline recommendations. A systematic review and meta-analysis. Diabetes Care, 37(4), 922-933. https://doi.org/10.2337/dc13-2195

Festinger, L. (1954). A theory of social comparison processes. Human Relations, 7(2), 117140.

Fredrix, M., Byrne, M., Dinneen, S., \& McSharry, J. (2018). “It's an important part, but I am not quite sure that it is working": educators' perspectives on the implementation of goal-setting within the 'DAFNE'diabetes structured education programme. Diabetic Medicine, 36(1), 80-87. https://doi.org/10.1111/dme.13813

Fu, D., Ding, Y., McGowan, P., \& Fu, H. (2006). Qualitative evaluation of Chronic Disease Self Management Program (CDSMP) in Shanghai. Patient Education and Counseling, 61(3), 389-396. https://doi.org/10.1016/j.pec.2005.05.002

Gallagher, R., Kirkness, A., Armari, E., \& Davidson, P. M. (2012). Participants' perspectives of a multi-component, group-based weight loss programme supplement for cardiac rehabilitation: A qualitative study. International Journal of Nursing Practice, 18(1), 28-35. https://doi.org/10.1111/j.1440-172X.2011.01988.x

Greaves, C. J., \& Campbell, J. L. (2007). Supporting self-care in general practice. The British Journal of General Practice, 57(543), 814-821.

Greaves, C. J., Sheppard, K. E., Abraham, C., Hardeman, W., Roden, M., Evans, P. H., \& Schwarz, P. (2011). Systematic review of reviews of intervention components associated with increased effectiveness in dietary and physical activity interventions. BMC Public Health, 11(1), 119. https://doi.org/10.1186/1471-2458-11-119

Hardcastle, S., \& Hagger, M. S. (2011). "You Can't Do It on Your Own": Experiences of a motivational interviewing intervention on physical activity and dietary behaviour. Psychology of Sport and Exercise, 12(3), 314-323. https://doi.org/10.1016/j.psychsport.2011.01.001 
1 Haslam, S. A., Jetten, J., Postmes, T., \& Haslam, C. (2009). Social identity, health and wellbeing: an emerging agenda for applied psychology. Applied Psychology, 58(1), 1-23. https://doi.org/10.1111/j.1464-0597.2008.00379.x

Haslam, C., Jetten, J., Cruwys, T., Dingle, G., \& Haslam, S. A. (2018). The new psychology of health: Unlocking the social cure. London: Routledge. Doi: 0.4324/9781315648569

Hoddinott, P., Allan, K., Avenell, A., \& Britten, J. (2010). Group interventions to improve health outcomes: a framework for their design and delivery. BMC Public Health, 10(1), 800. https://doi.org/10.1186/1471-2458-10-800

Hogan, B. E., Linden, W., \& Najarian, B. (2002). Social support interventions: Do they work? Clinical Psychology Review, 22(3), 381-440. https://doi.org/10.1016/S0272$\underline{7358(01) 00102-7}$

Hughes, S., Lewis, S., Willis, K., Rogers, A., Wyke, S., \& Smith, L. (2018). How do facilitators of group programmes for long-term conditions conceptualise selfmanagement support? Chronic Illness, 1742395318792068.

Kok, M. S., Bryant, L., Cook, C., Blackmore, S., \& Jones, M. (2019, March). Integrating local knowledge into a national programme: Evidence from a community-based diabetes prevention education programme. Healthcare, 7(1), 38. https://doi.org/10.3390/healthcare7010038

Ljung, S., Olsson, C., Rask, M., \& Lindahl, B. (2013). Patient experiences of a theory-based lifestyle-focused group treatment in the prevention of cardiovascular diseases and Type 2 Diabetes. International Journal of Behavioral Medicine, 20(3), 378-384. https://doi.org/10.1007/s12529-012-9252-3

McBride, C. M., Emmons, K. M., \& Lipkus, I. M. (2003). Understanding the potential of teachable moments: the case of smoking cessation. Health Education Research, 18(2), 156-170. https://doi.org/10.1093/her/18.2.156

Metzgar, C. J., Preston, A. G., Miller, D. L., \& Nickols-Richardson, S. M. (2014). Facilitators and barriers to weight loss and weight loss maintenance: a qualitative exploration. Journal of Human Nutrition and Dietetics, 28(6), 593-603. https://doi.org/10.1111/jhn.12273

Murphy, S. A., \& Johnson, L. C. (2006). Methodological issues associated with group intervention research. Archives of Psychiatric Nursing, 20(6), 276-281. https://doi.org/10.1016/j.apnu.2006.05.003 
1 Murray, N. J., Abadi, S., Blair, A., Dunk, M., \& Sampson, M. J. (2011). The importance of type 2 diabetes prevention: The Norfolk Diabetes Prevention Study. The British Journal of Diabetes \& Vascular Disease, 11(6), 308-313.

Nackers, L. M., Dubyak, P. J., Lu, X., Anton, S. D., Dutton, G. R., \& Perri, M. G. (2015). Group dynamics are associated with weight loss in the behavioral treatment of obesity. Obesity, 23(8), 1563-1569. https://doi.org/10.1002/oby.21148

Odgers-Jewell, K., Ball, L. E., Kelly, J. T., Isenring, E. A., Reidlinger, D. P., \& Thomas, R. (2017). Effectiveness of group-based self-management education for individuals with Type 2 diabetes: a systematic review with meta-analyses and meta-regression.

Diabetic Medicine, 34(8), 1027-1039. https://doi.org/10.1111/dme.13340

Olander, E. K., Fletcher, H., Williams, S., Atkinson, L., Turner, A., \& French, D. P. (2013). What are the most effective techniques in changing obese individuals' physical activity self-efficacy and behaviour: a systematic review and meta-analysis. International Journal of Behavioral Nutrition and Physical Activity, 10, 29. https://doi.org/10.1186/1479-5868-10-29

Pascale, M., Murray, N., Bachmann, M., Barton, G., Clark, A., Howe, A., ... Sampson, M. (2017). Study Protocol: The Norfolk Diabetes Prevention Study [NDPS]: a 46 month multi-centre, randomised, controlled parallel group trial of a lifestyle intervention [with or without additional support from lay lifestyle mentors with Type 2 diabetes] to prevent transition to Type 2 diabetes in high risk groups with non-diabetic hyperglycaemia, or impaired fasting glucose. BMC Public Health, 17(1), 31. https://doi.org/10.1186/s12889-016-3929-5

Penn, L., Dombrowski, S. U., Sniehotta, F. F., \& White, M. (2013). Participants’ perspectives on making and maintaining behavioural changes in a lifestyle intervention for type 2 diabetes prevention: a qualitative study using the theory domain framework. BMJ Open, 3(6), e002949. http://dx.doi.org/10.1136/bmjopen-2013-002949

Penn, L., Rodrigues, A., Haste, A., Marques, M., Budig, K., Sainsbury, K., Bell, R., AraujoSoares, V., White, M., Summerbell, C., Goyder E., Brennan, A., Adamson, A., \& Sniehotta, F. (2018) NHS Diabetes Prevention Programme in England: formative evaluation of the programme in early phase implementation. BMJ Open, 8, e019467. http://dx.doi.org/10.1136/bmjopen-2017-019467

Rogers, A., Gately, C., Kennedy, A., \& Sanders, C. (2009). Are some more equal than others? Social comparison in self-management skills training for long-term 
conditions. Chronic Illness, 5(4), 305-317. https://doi.org/10.1177/1742395309350384

Schwarz, P. E., Greaves, C. J., Lindström, J., Yates, T., \& Davies, M. J. (2012). Nonpharmacological interventions for the prevention of type 2 diabetes mellitus. Nature Reviews Endocrinology, 8(6), 363-373. https://doi.org/10.1038/nrendo.2011.232

Sebire, S. J., Toumpakari, Z., Turner, K. M., Cooper, A. R., Page, A. S., Malpass, A., \& Andrews, R. C. (2018). "I've made this my lifestyle now": a prospective qualitative study of motivation for lifestyle change among people with newly diagnosed type two diabetes mellitus. BMC Public Health, 18(1), 204. https://doi.org/10.1186/s12889$\underline{018-5114-5}$

Sharma, M. (2007). Behavioural interventions for preventing and treating obesity in adults. Obesity Reviews, 8(5), 441-449. https://doi.org/10.1111/j.1467-789X.2007.00351.X Smith, P. B. (1980). Group processes and personal change. London: Harper and Row.

Tarrant, M., Hagger, M. S., \& Farrow, C. V. (2012). Promoting positive orientation towards health through social identity. In J. Jetten, C. Haslam, \& S. A. Haslam (Eds.), The Social Cure: Identity, Health and Well-being. London: Psychology Press.

Tarrant, M., Khan, S., Farrow, C., Shah, P., Daly, M., \& Kos, K. (2017). Patient experiences of a bariatric group programme for managing obesity: A qualitative interview study. British Journal of Health Psychology, 22, 77-93. https://doi.org/10.1111/bjhp.12218

Tarrant, M., Warmoth, K., Code, C., Dean, S., Goodwin, V., Stein, K., \& Sugavanam, T. (2016). Creating psychological connections between intervention recipients: Development and focus group evaluation of a group singing session for people with aphasia. BMJ Open, 6, e009652. https://doi.org/doi:10.1136/bmjopen-2015-009652

Vähäsarja, K., Kasila, K., Kettunen, T., Rintala, P., Salmela, S., \& Poskiparta, M. (2015). “I saw what the future direction would be...": Experiences of diabetes risk and physical activity after diabetes screening. British Journal of Health Psychology, 20(1), 172193. https://doi.org/10.1111/bjhp.12088

Wakefield, J. R., Bickley, S., \& Sani, F. (2013). The effects of identification with a support group on the mental health of people with multiple sclerosis. Journal of Psychosomatic Research, 74(5), 420-426. https://doi.org/10.1016/j.jpsychores.2013.02.002

World Health Organization. (2013). Global action plan for the prevention and control of noncommunicable diseases 2013-2020. Geneva, World Health Organization. 
1 Youngs, W., Gillibrand, W. P., \& Phillips, S. (2016). The impact of pre-diabetes diagnosis on 2 behaviour change: an integrative literature review. Practical Diabetes, 33(5), 171-

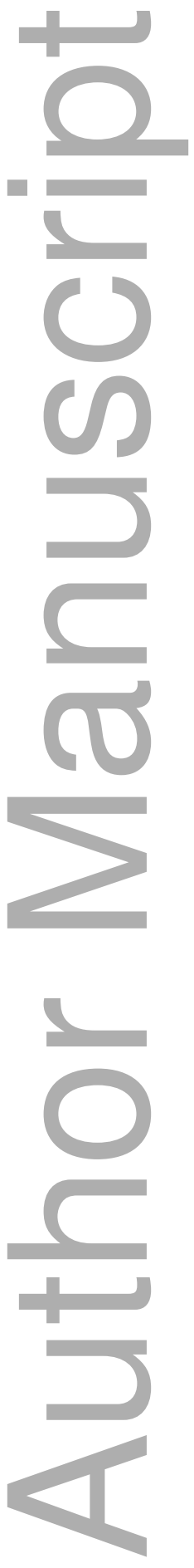




\section{Figures}

2 Figure 1. Schematic summary of the interview themes

\begin{tabular}{|l|}
\hline \multicolumn{1}{c|}{ 1. Participants' } \\
motivations \\
- Improving health \\
\& preventing or \\
controlling diabetes \\
- Losing weight \\
- Contributing to research \\
- Intrinsic motivation \\
- Post-diagnostic motivation \\
\hline
\end{tabular}

\begin{tabular}{|l|}
\hline \multicolumn{1}{|c}{ 2. Change } \\
\multicolumn{1}{|c|}{ Individual change } \\
processes \\
- Information provision \\
- Structuring \& \\
prioritising health goals \\
- Action planning \\
- Self-monitoring \\
- Receiving feedback
\end{tabular}

\begin{tabular}{|c|}
\hline \multicolumn{1}{|c|}{ Group change } \\
processes \\
- Common purpose \\
- Sharing experiences \\
- Social comparisons \\
- Monitoring \& \\
accountability \\
- Social support \\
\hline
\end{tabular}

5. Impact of group
participation
Positive experiences
Negative experiences
Taking responsibility
Reported behaviour change
Weight loss \& improved
health

10

11
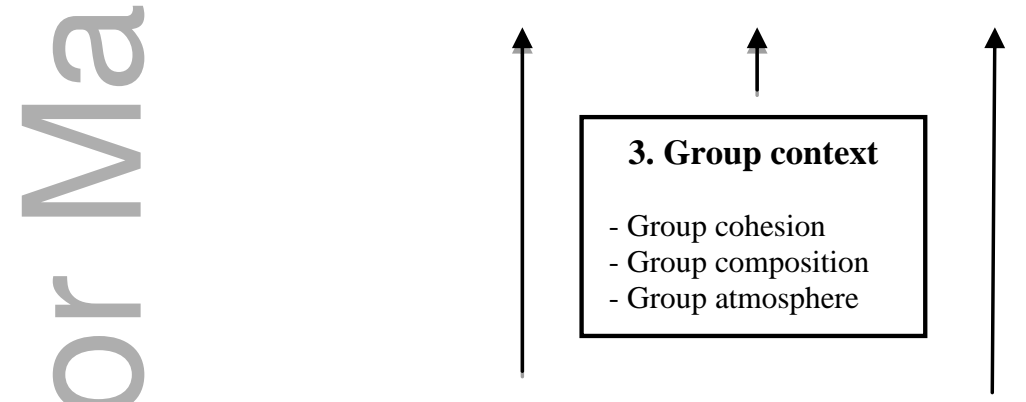

Group atmosition
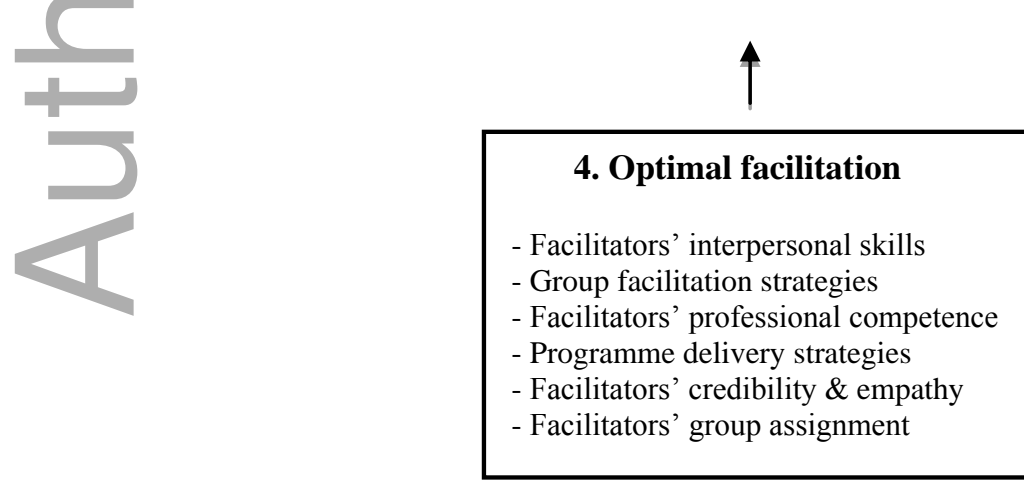

This article is protected by copyright. All rights reserved 


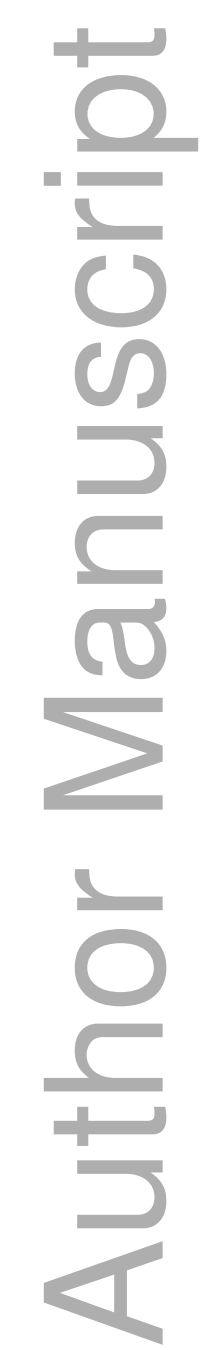

This article is protected by copyright. All rights reserved 


\section{$1 \quad$ List of Additional Files}

2

3 Additional Document 1. Interview Topic Guide

4 This document includes the interview topic guide used to conduct the semi-structured

5 telephone interviews in this study.

6

7 Additional Document 2. Participants' Characteristics

8 This document includes a summary of participants' characteristics: gender, age, ethnicity,

$9 \mathrm{BMI}$ at baseline and post-education sessions, session attendance and diabetes status. 10

11 Additional Document 3. Interview Quotes Supporting Identified Themes

12 This document includes interview quotes illustrating the identified themes and supporting 13 the analyses presented in the results.

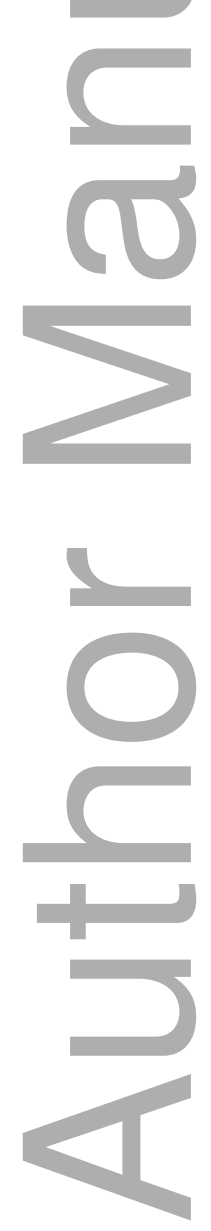




\section{University Library}

\section{- M M N E R VA A gateway to Melbourne's research publications}

Minerva Access is the Institutional Repository of The University of Melbourne

\section{Author/s:}

Borek, AJ;Abraham, C;Greaves, CJ;Tarrant, M;Garner, N;Pascale, M

Title:

'We're all in the same boat': A qualitative study on how groups work in a diabetes prevention and management programme

\section{Date:}

2019-11-01

\section{Citation:}

Borek, A. J., Abraham, C., Greaves, C. J., Tarrant, M., Garner, N. \& Pascale, M. (2019).

'We're all in the same boat': A qualitative study on how groups work in a diabetes prevention and management programme. BRITISH JOURNAL OF HEALTH PSYCHOLOGY, 24 (4), pp.787-805. https://doi.org/10.1111/bjhp.12379.

Persistent Link:

http://hdl.handle.net/11343/286892 